\title{
Galectin-1 and galectin-3 in the corpus luteum of mice are differentially regulated by prolactin and prostaglandin $F_{2 \alpha}$
}

\author{
Junko Nio-Kobayashi and Toshihiko Iwanaga \\ Laboratory of Histology and Cytology, Hokkaido University Graduate School of Medicine, Kita 15-Nishi 7, \\ Kita-ku, Sapporo 060-8638, Japan \\ Correspondence should be addressed to J Nio-Kobayashi; Email: niojun@med.hokudai.ac.jp
}

\begin{abstract}
Galectin-1 and galectin-3, $\beta$-galactoside-binding lectins, are specifically expressed in the regressing corpus luteum (CL) of mice; however, their function remains unclear. In this study, we examined the effects of prolactin (PRL) and prostaglandin $\mathrm{F}_{2 \alpha}\left(\mathrm{PGF}_{2 \alpha}\right)$, two main regulatory molecules of mouse $C L$ function, on galectin expression. In situ hybridization analysis clearly demonstrated an initial increase in galectin-1 in the newly formed CL (CLN) after postpartum ovulation $48 \mathrm{~h}$ after compulsory weaning. This was accompanied by

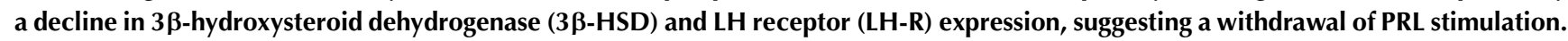
At $72 \mathrm{~h}$ after the weaning, the expression of both galectins in CLN was remarkably increased, being associated with an intense expression of progesterone degradation enzyme (20 $\alpha-\mathrm{HSD})$. Compulsory weaning did not significantly alter both galectin expression in the remaining $\mathrm{CL}$ of pregnancy (CLP), while $\mathrm{PGF}_{2 \alpha}$ strongly upregulated both galectin expression only in the remaining CLP, which lacked LH-R in postpartum mice. Administration of bromocriptine, an antagonist for PRL secretion, to nonpregnant cyclic mice induced an accumulation of galectin-1 - but not galectin-3 - in all CL of various generations, and additional PRL treatment reduced its accumulation, suggesting a direct suppressive effect of PRL on galectin-1 expression. Although the function and regulatory mechanism of galectin in the $\mathrm{CL}$ is not fully understood, $\mathrm{PGF}_{2 \alpha}$ is an excellent candidate that regulates galectin expression, but its effect may be abolished by LH-R-mediated signal. PRL withdrawal seems to be necessary for an initiation of luteolysis and the following PGF $_{2 \alpha}$-induced galectin expression.
\end{abstract}

Reproduction (2012) 144 617-624

\section{Introduction}

Galectin is a $\beta$-galactoside-binding animal lectin involved in various physiological and pathological events regulating cell proliferation, differentiation, migration, and apoptosis. Fifteen members of galectin family have been identified in mammalian tissues, and the predominant subtypes expressed in the mouse ovary are galectin-1 and galectin-3 (Nio \& Iwanaga 2007). Recently, we demonstrated that both galectin subtypes in the corpus luteum $(\mathrm{CL})$ of mice showed a stage- and cell-specific expression pattern during the estrous cycle, and their expression was especially intense in the regressing $\mathrm{CL}$, which contains a progesterone degradation enzyme - 20 $\alpha$-hydroxysteroid dehydrogenase

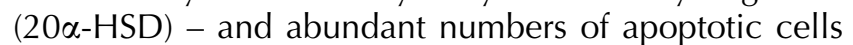
(Nio-Kobayashi \& Iwanaga 2010). Although the characteristic expression of galectins in the regressing $\mathrm{CL}$ confirms their contribution to luteolysis, the function and regulation of galectin in the ovary remains unclear.

In rodents, luteolysis is characterized by an initial decline in progesterone secretion that is commonly designated as functional luteolysis, which is distinct from structural luteolysis that signifies the subsequent structural change with its gradual involution to form a small scar composed of connective tissue (Bachelot \& Binart 2005). Functional luteolysis is accompanied by the expression of $20 \alpha-\mathrm{HSD}$, whereas the structural luteolysis is characterized by apoptosis of luteal cells. CL function in rodents is regulated by two main factors: prolactin (PRL) from the pituitary gland and prostaglandin $F_{2 \alpha}$ $\left(\mathrm{PGF}_{2 \alpha}\right)$ from the uterus. PRL is a main luteotropic hormone, and it induces gene expression essential for progesterone production, such as $3 \beta$-hydroxysteroid dehydrogenase ( $3 \beta-\mathrm{HSD})$ and $\mathrm{LH}$ receptor $(\mathrm{LH}-\mathrm{R})$. PRL also possesses a luteolytic role when the $\mathrm{CL}$ cease to produce progesterone by expressing $20 \alpha-\mathrm{HSD}$ (Stocco et al. 2007). It is currently believed that the pre-ovulatory surge of PRL on the evening of proestrus causes apoptosis of luteal cells, and thus structural luteolysis, in the CL during estrous cycles of nonpregnant mice (Gaytán et al. 2001). On the other hand, $\mathrm{PGF}_{2 \alpha}$ plays a crucial role in the functional luteolysis by inducing $20 \alpha-H S D$ expression.

Galectin modulates transductions of various signals by recognizing $\beta$-galactoside of glycoconjugates on cell 
surface and extracellular matrix to regulate cell viability and motility. Because various factors regulating angiogenesis, immune cell function, and cancer progression and metastasis are involved in luteolysis, elucidating the role and regulation of galectin in luteolysis should provide the valuable information regarding the fundamental role of galectin and its carbohydrate ligands in mammals. Our recent report demonstrated a biphasic expression of galectin- 1 in the mouse $\mathrm{CL}$ during the estrous cycle (Nio-Kobayashi \& Iwanaga 2010). The first and temporal increase in galectin-1 expression occurred on the second day after ovulation preceding the expression of $20 \alpha-H S D$, namely functional luteolysis. The mRNA expression of galectin-1 was again increased in the structurally regressing $\mathrm{CL}$, which also intensely expressed galectin-3 and 20 $\alpha$-HSD and contained abundant numbers of apoptotic luteal cells. The dramatic change in the galectin expression during $\mathrm{CL}$ formation and regression suggests that ovarian galectin-1 and galectin- 3 may be regulated by PRL and/or $\mathrm{PGF}_{2 \alpha}$ and differentially contribute to the control of luteolysis. This study aimed to elucidate whether PRL and/or $\mathrm{PGF}_{2 \alpha}$ regulate the expression of galectin in the $\mathrm{CL}$ of mice by analyzing the effect of following treatments: i) compulsory weaning of postpartum mice to reduce plasma PRL concentration as serum PRL level is elevated by suckling in lactating animals after parturition (Taya \& Greenwald 1982); ii) PGF $_{2 \alpha}$ administration to pregnant and postpartum mice; iii) withdrawal of progesterone in pregnant mice by administration of a progesterone receptor antagonist (mifepristone/RU486) to evaluate an indirect regulation of galectin expression by luteal progesterone, which is altered by $\mathrm{PRL}$ and/or $\mathrm{PGF}_{2 \alpha i}$; iv) bromocriptine administration to suppress the secretion of PRL from the pituitary gland in nonpregnant cyclic mice to confirm the effect of PRL on galectin expression.

\section{Results \\ Effect of compulsorily weaning on galectin expression in the ovary of postpartum mice}

As postpartum ovulation occurs within $24 \mathrm{~h}$ after parturition, newly formed $\mathrm{CL}(\mathrm{CLN})$ and the remaining $\mathrm{CL}$ of pregnancy $(\mathrm{CLP})$ are intermingled in the postpartum ovary (Connor \& Davis 1980). Only the CLP expressed galectin-3 and $20 \alpha-\mathrm{HSD}$ in lactating mice as we previously reported (Nio \& Iwanaga 2007). To elucidate the effect of PRL on galectin expression in the $C L$, we examined changes in the expression of mRNA for galectins and related molecules in the ovaries of compulsorily weaned mice. No significant changes could be found in the ovary $24 \mathrm{~h}$ after the weaning in both CLN and CLP (Fig. 1A, B, C, D and E). Namely, galectin-3/20 $\alpha-H S D$-negative CLN (arrows in Fig. 1B and $\mathrm{C}$ ) and galectin-3/20 $\alpha$-HSD-positive CLP (asterisks in Fig. 1B and C) intermingled as so do in the ovary of lactating mice. The expression of $3 \beta-\mathrm{HSD}$ was intense in all CL (Fig. 1D), whereas LH-R was expressed only in the CLN (arrows in Fig. 1E). The gene expression patterns indicated differential status of these CL: the CLN, corresponding to the $\mathrm{CL}$ of lactation that have been over-stimulated by $\mathrm{PRL}$, are functional $\mathrm{CL}$ actively producing progesterone, while the remaining CLP is undergoing functional luteolysis. At $48 \mathrm{~h}$ after the weaning, a remarkable change in the gene expression was observed in the CLN. The expression of galectin- 1 in the CLN increased in intensity associated with a significant expression of $20 \alpha-H S D$, indicating the start of functional luteolysis (arrows in Fig. 1F and $\mathrm{H}$ ). At this stage, the intensity of the expression of $3 \beta-\mathrm{HSD}$ and $\mathrm{LH}-\mathrm{R}$ decreased in the CLN (arrows in Fig. $1 \mathrm{I}$ and J), suggesting a withdrawal of PRL stimulation, while $3 \beta-H S D$ expression was still high in the CLP (asterisks in Fig. 1I). Intense expression of both galectin- 1 and galectin- 3 in the CLN was observed at $72 \mathrm{~h}$ after the weaning associated with marked expression of $20 \alpha-\mathrm{HSD}$ and weak or no expression of $3 \beta-H S D$ and LH-R (arrows in Fig. $1 K, L, M, N$ and $\mathrm{O}$ ). On the other hand, the expression of both galectins in the CLP was slightly reduced $48 \mathrm{~h}$ after the weaning (asterisks in Fig. 1F and G) and became intense at $72 \mathrm{~h}$ (asterisks in Fig. $1 \mathrm{~K}$ and $\mathrm{L}$ ), although the signals in the CLP were less intense than those in the CLN. The changes in the gene expression caused by compulsory weaning are shown in Fig. 1P and Q.

These observations indicate that an initial increase in galectin-1 expression in the CLN was accompanied by a decline in the expression of both $3 \beta-H S D$ and LH-R, implying a withdrawal of PRL stimulation by compulsory weaning. The further increase in galectin-1 $72 \mathrm{~h}$ after the weaning was associated with intense expressions of $20 \alpha-H S D$ and galectin-3. As the effect of compulsory weaning on galectin expression differed between the CLN and CLP, and there was a time-lag in the expression of each galectin in the CLN of compulsorily weaned mice, the effect of PRL seems to differ with regard to galectin- 1 and galectin-3 as well as to the status of the CL.

\section{Effect of $P G F_{2 \alpha}$ injection on galectin expression in the ovaries of pregnant and postpartum mice}

It is well established that the synthesis of $20 \alpha-\mathrm{HSD}$ in rodent $\mathrm{CL}$ is regulated by $\mathrm{PGF}_{2 \alpha}$ possibly released from the uterus. As galectin-3 and $20 \alpha-\mathrm{HSD}$ are concomitantly expressed in the regressing $\mathrm{CL}$ (Nio \& Iwanaga 2007), we hypothesized that galectin-3 would also be regulated by $\mathrm{PGF}_{2 \alpha}$. To investigate this, we examined the effect of $\mathrm{PGF}_{2 \alpha}$ treatment on galectin-3 expression in the late CLP (pregnancy day 17.5), which lacks both galectins and 20 $\alpha-\mathrm{HSD}$ (Fig. 2A, B and C). Contrary to our expectations, $\mathrm{PGF}_{2 \alpha}$ administration did not induce galectin-3 expression in the functional CLP of pregnant mice (Fig. 2B and F), although 20 $\alpha$-HSD expression was slightly increased by $\mathrm{PGF}_{2 \alpha}$ treatment in these $\mathrm{CL}$ 


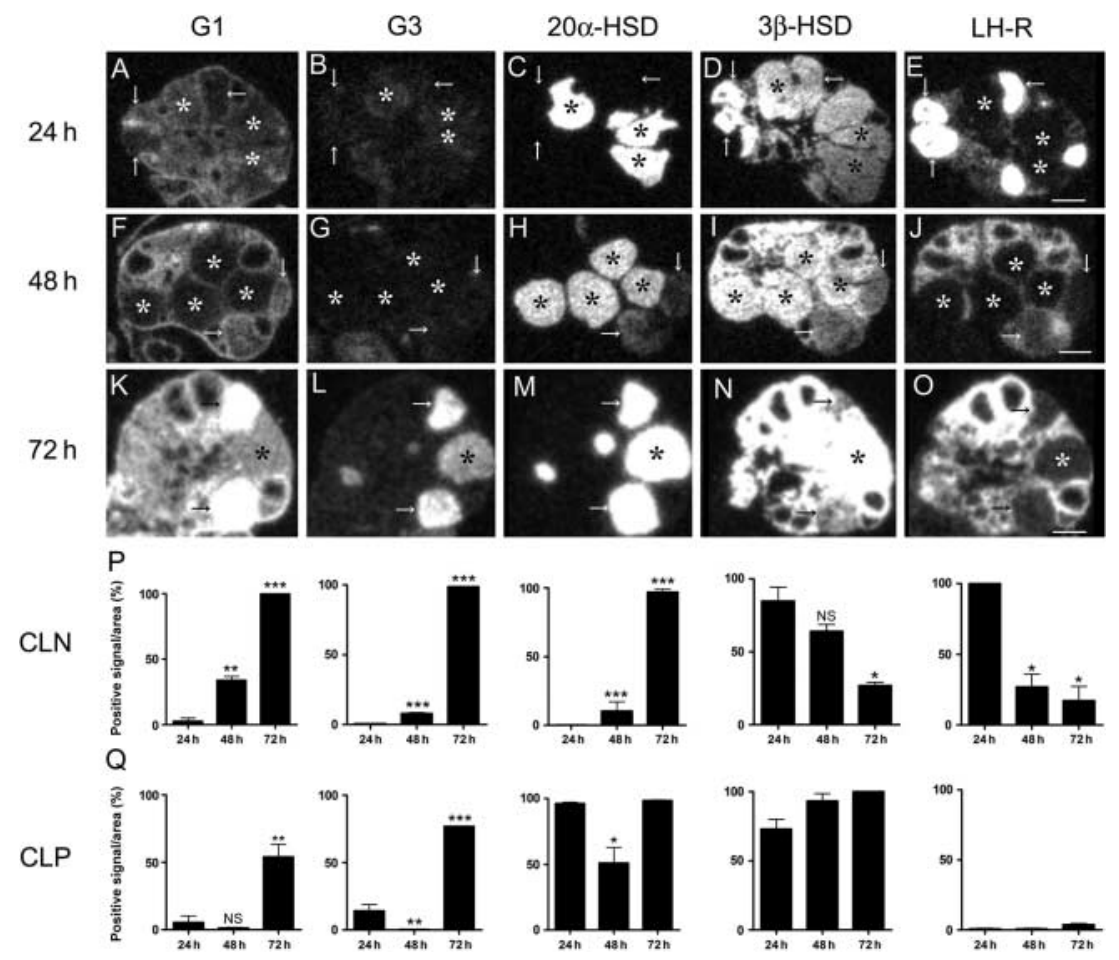

Figure 1 Changes in the expression of galectins and related molecules in the ovaries of compulsorily weaned mice. Two types of $\mathrm{CL}$ intermingle in the postpartum ovary: CL newly formed at postpartum ovulation (CLN, arrows) and remaining CL of pregnancy under a functional regressing stage (CLP, asterisks). Like the lactating mouse ovary, galectin-3 (G3) and $20 \alpha$-hydroxysteroid dehydrogenase (20 $\alpha$-HSD) mRNAs are expressed only in the CLP (asterisks in B and C), whereas signals for LH receptor (LH-R) are found only in the CLN (arrows in E) at $24 \mathrm{~h}$ after the weaning. At this stage,

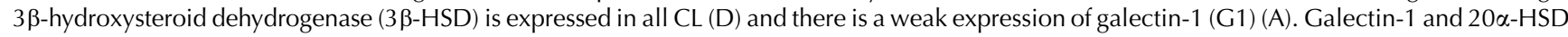
mRNAs increase $48 \mathrm{~h}$ after the weaning in the CLN (arrows in F and $\mathrm{H}$ ) when both the signals for $3 \beta-\mathrm{HSD}$ and $\mathrm{LH}-\mathrm{R}$ are decreasing (arrows in I and $\mathrm{J}$ ). Galectin-3 expression in CLP is slightly reduced $48 \mathrm{~h}$ after the weaning (asterisks in M). After $72 \mathrm{~h}$ from the weaning, both galectin- 1 and galectin-3 are intensely expressed in the CLN (arrows in $\mathrm{K}-\mathrm{M}$ ) as well as in the CLP (asterisks in $\mathrm{K}-\mathrm{M}$ ), although the expressions of both $3 \beta-\mathrm{HSD}$ and LH-R have almost disappeared from the CLN (arrows in $\mathrm{N}$ and $\mathrm{O}$ ). The percentages of the positive signals per area for each gene in the CLN and CLP are summarized in $\mathrm{P}$ and $\mathrm{Q}$. Asterisks in $\mathrm{P}$ and $\mathrm{Q}$ show the significant difference compared with the signals at $24 \mathrm{~h}$ after the weaning. ${ }^{*} P<0.05$, ${ }^{* *} P<0.01,{ }^{* * *} P<0.001$ respectively. NS, not significant. Bars $=0.5 \mathrm{~mm}$.

(Fig. 2C and G). There were no significant effects of $\mathrm{PGF}_{2 \alpha}$ on the expression of both galectin-1 (Fig. 2A and $\mathrm{E}$ ) and LH-R in the functional CLP (Fig. 2D and $\mathrm{H}$ ). On the other hand, when $\mathrm{PGF}_{2 \alpha}$ was administrated to postpartum mice at day 3 , the expression of galectin-3 remarkably increased only in the remaining CLP, which intensely expressed 20 $\alpha$-HSD but lacked LH-R (asterisks in Fig. 2J, K, L, N, O and P). Galectin-3 in the CLN with intense expression of LH-R was not affected by $\mathrm{PGF}_{2 \alpha}$ (arrows in Fig. 2), K, L, N, O and P). Galectin-1 expression also increased in intensity in the remaining CLP by $\mathrm{PGF}_{2 \alpha}$ administration (asterisks in Fig. $2 \mathrm{I}$ and $\mathrm{M}$ ) but again did not change in the CLN (arrows in Fig. 2I and $M$ ). These findings indicate that galectin-3, as well as galectin-1, is upregulated by $\mathrm{PGF}_{2 \alpha}$ only when $\mathrm{CL}$ does not express LH-R.

\section{Effect of mifepristone (RU486) administration on galectin expression in the functional CLP}

To clarify whether progesterone could influence galectin expression, we administrated a progesterone receptor antagonist to mice at day 17.5 of pregnancy. There were no significant changes in the expression of galectin, $3 \beta$-HSD, 20 $\alpha$-HSD, or LH-R $12 \mathrm{~h}$ after mifepristone treatment (Fig. 3, controls were shown in Fig. 2A, B, C and $\mathrm{D}$ ), suggesting that PRL and/or $\mathrm{PGF}_{2 \alpha}$ may not indirectly regulate galectin expression via alternations in progesterone production.

\section{Effect of bromocriptine administration on the expression of galectins in the ovary of nonpregnant cyclic mice}

As the increased expression of galectin-1 mRNA in weaned mice was accompanied by a reduction of $3 \beta-$ HSD and LH-R, which are known to be upregulated by PRL, it is anticipated that a decrease in a PRL signal would induce the expression of galectin- 1 in the CL. We therefore examined the effect of continuous administration of bromocriptine, which suppresses the secretion of PRL from the pituitary gland, and the effect of an additional PRL treatment on luteal galectin expression. Because PRL is known to induce structural luteolysis 

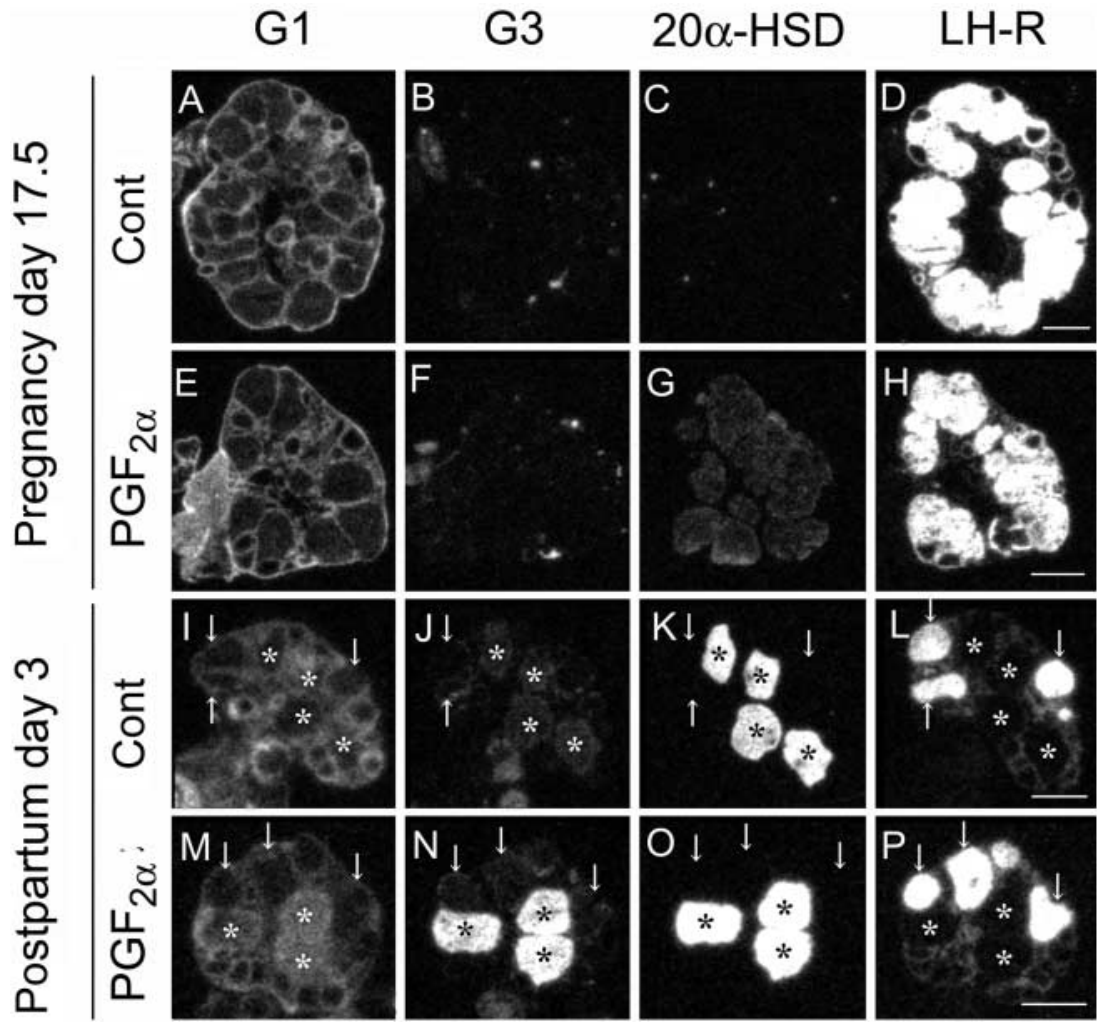
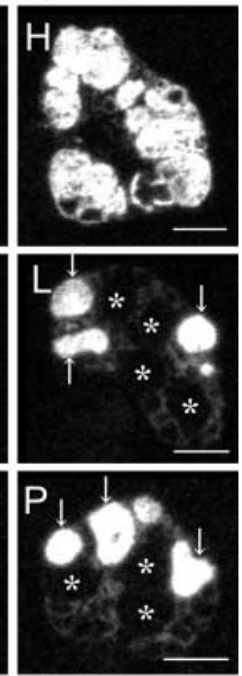

Figure 2 Effect of $\mathrm{PGF}_{2 \alpha}$ on galectin expression in the ovaries of pregnant and postpartum mice. $\mathrm{PGF}_{2 \alpha}$ administration to pregnant mice (day 17.5) has no effect on the expression of either galectin or $\mathrm{LH}-\mathrm{R}(\mathrm{A}, \mathrm{B}, \mathrm{C}, \mathrm{D}, \mathrm{E}, \mathrm{F}, \mathrm{G}$ and $\mathrm{H})$ in all $\mathrm{CL}$ whereas the signals for $20 \alpha-H S D$ are slightly increased (G). On the other hand, both galectin-1 and galectin-3 are increased in the remaining CLP of postpartum mice (day 3) by $\mathrm{PGF}_{2 \alpha}$ treatment (asterisks in I, J, $\mathrm{M}$ and $\mathrm{N}$ ). These $\mathrm{CL}$ intensely express $20 \alpha-\mathrm{HSD}$ (asterisks in $\mathrm{K}$ and $\mathrm{O}$ ) but lack LH-R (asterisks in $\mathrm{L}$ and $\mathrm{P}$ ). Bars $=1 \mathrm{~mm}$. when the $\mathrm{CL}$ cease progesterone production, we first expected that bromocriptine treatment must prevent the $\mathrm{CL}$ from undergoing structural luteolysis. However, it does not influence on the rate of ovulation. Thus, the ovaries of the bromocriptine-treated mice contained several generations of cyclic $\mathrm{CL}$ : the functional $\mathrm{CL}$ formed at the latest estrous cycle and old regressing $\mathrm{CL}$ under functional but not structural regressing stage formed during previous estrous cycles. The weight of the ovaries was significantly higher in the bromocriptinetreated mice compared with both control (normal cyclic) and bromocriptine plus PRL-treated mice, corresponding to the previous report by Gaytán et al. (2001).

The continuous administration of bromocriptine induced an accumulation of galectin- 1 mRNA in all $\mathrm{CL}$ (Fig. 4A) while the loss of PRL signaling reduced the expressions of both $3 \beta-H S D$ and LH-R (Fig. $4 \mathrm{C}$ and D). PRL administration to the bromocriptine-treated mice resulted in a recovery of the expression of $3 \beta-\mathrm{HSD}-$ but not that of $\mathrm{LH}-\mathrm{R}$ - and a simultaneous reduction in galectin- 1 accumulation in the $\mathrm{CL}$ (Fig. $4 \mathrm{E}, \mathrm{G}$ and $\mathrm{H}$ ).
There were no significant changes in the expression of galectin-3 in either bromocriptine- or bromocriptine plus PRL-treated mice (Fig. 4B and F).

Immunohistochemical analysis revealed an accumulation of galectin- 1 protein in both functional and old regressing $\mathrm{CL}$ in the ovaries of bromocriptine-treated mice (Fig. $4 \mathrm{I}$ and J), although the newly formed $\mathrm{CL}$ (asterisks in Fig. $4 \mathrm{l}, \mathrm{J}, \mathrm{K}$ and $\mathrm{L}$ ) possessed less intense immunoreactions both for galectin- 1 and galectin- 3 than those in the old regressing $\mathrm{CL}$. These findings suggest that galectin- 1 is negatively regulated by PRL but galectin- 3 expression is not affected by PRL.

\section{Discussion}

Although the regulation of luteolysis is complicated and its exact mechanism remains to be elucidated, PRL and $\mathrm{PGF}_{2 \alpha}$ are likely to be main regulatory molecules of the $\mathrm{CL}$ function in mice. A remarkable change in the expression of galectin during the estrous cycle associated with an intense expression in the regressing $\mathrm{CL}$
Pregnancy day 17.5
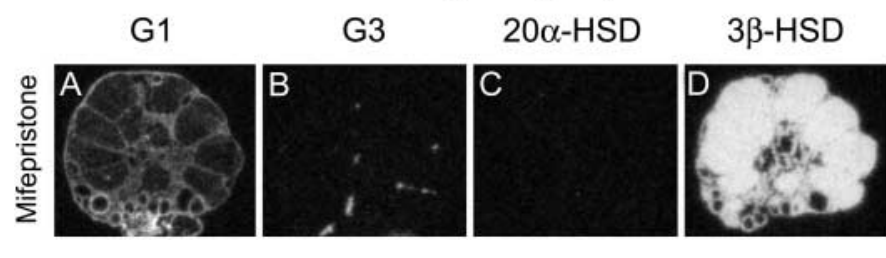

Figure 3 Effect of mifepristone on galectin expression in pregnant mice (at day 17.5).

Administration of mifepristone does not alter the expression of galectin or $20 \alpha-\mathrm{HSD}$ and has no influence on the expression of both $3 \beta-H S D$ and LH-R in all CL of pregnancy (A, B, C, D and E). Bar $=1 \mathrm{~mm}$. 

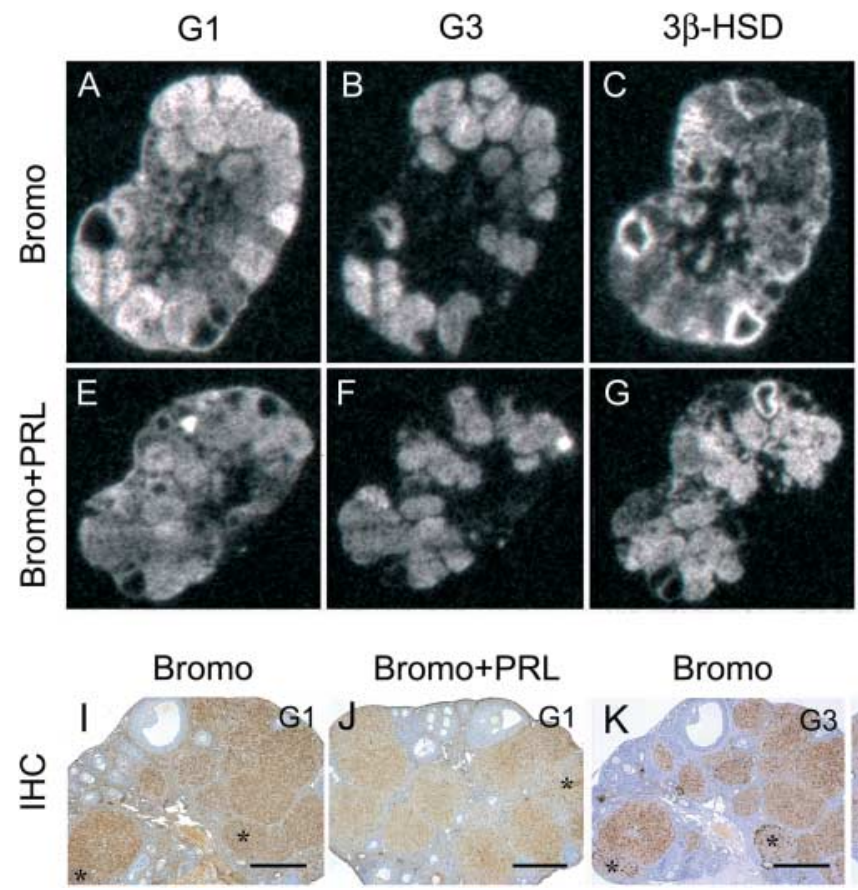

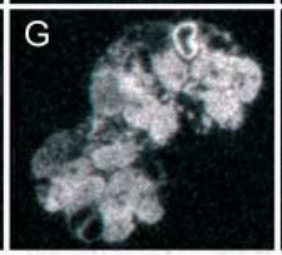

Bromo

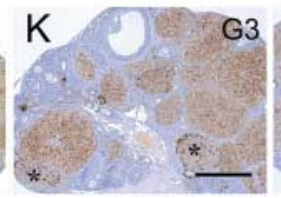

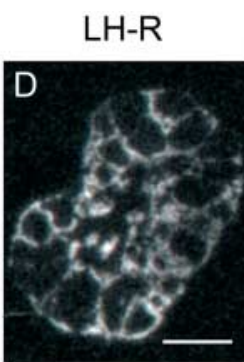

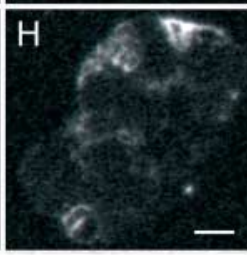

Bromo+PRL

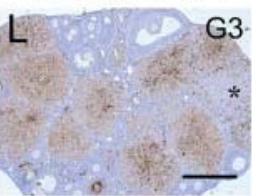

Figure 4 Changes in the expression of galectins, $3 \beta-H S D$, and LH-R in the bromocriptine-treated mice. When bromocriptine (Bromo) is administrated for 10 days, an accumulation of galectin-1 (G1) mRNA in the CL is observed (A) whereas signals for both $3 \beta-H S D$ and LH-R are negligible in all $\mathrm{CL}(\mathrm{C}$ and $\mathrm{D})$. Prolactin (PRL) treatment in the bromocriptine-administrated mice at day 9 inhibits the accumulation of galectin- 1 and restores the expression of $3 \beta-\mathrm{HSD}$ but not that of LH-R (E, G and H). Galectin-3 (G3) is not significantly affected by either bromocriptine or bromocriptine plus PRL treatment (B and $\mathrm{F}$ ). Immunohistochemical (IHC) analysis shows an accumulation of galectin- 1 in all $C L$ of bromocriptine-treated mice (I and J); however, galectin-3 staining does not significantly alter by the treatment ( $\mathrm{K}$ and $\mathrm{L}$ ). Asterisks in I, J, K and L indicate the functional $\mathrm{CL}$ formed at the latest estrous cycle. Bars $=0.5 \mathrm{~mm}$. suggests an involvement of galectin in the PRL- and $\mathrm{PGF}_{2 \alpha}$-regulated luteolysis. In this study, we found for the first time that $\mathrm{PGF}_{2 \alpha}$ was an excellent candidate for a molecular regulation of the expression of both galectin- 1 and galectin-3 in the $\mathrm{CL}$, although its effect was dependent on the status of the $\mathrm{CL}$. When the $\mathrm{CL}$ intensely expressed $\mathrm{LH}-\mathrm{R}, \mathrm{PGF}_{2 \alpha}$ failed to induce the expression of either galectin. On the other hand,
PRL seems to suppress the expression of galectin- 1 but not that of galectin-3, suggesting differential regulatory mechanisms between galectin- 1 and galectin-3 in the regressing $\mathrm{CL}$.

As summarized in Fig. 5A, galectin-1 showed a biphasic expression pattern in the compulsorily weaned mice as previously reported by us in nonpregnant cyclic mice (Nio-Kobayashi \& Iwanaga 2010). The first small

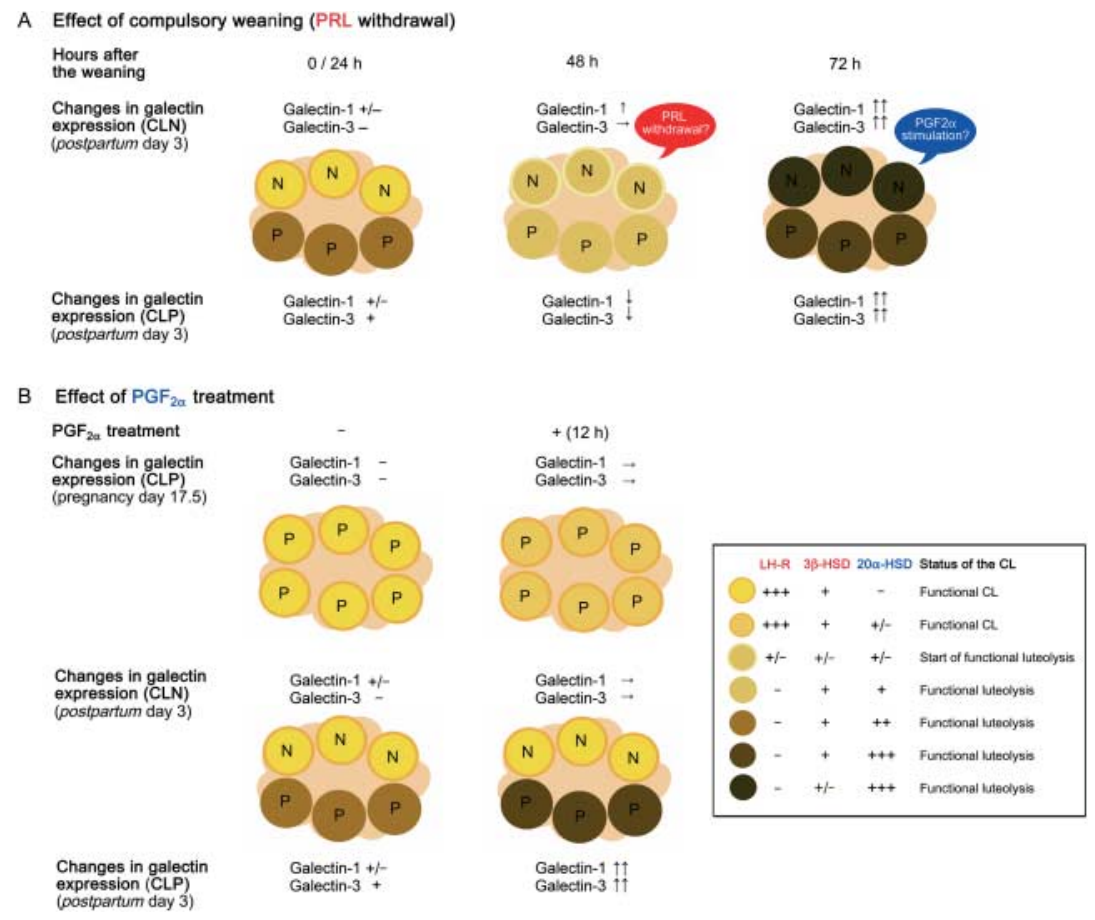

Figure 5 A schema summarizing the effect of compulsory weaning (A) and $\mathrm{PGF}_{2 \alpha}$ administration (B). Arrows indicate an increase or a decrease in the galectin expression compared with the expression in the $\mathrm{CL}$ at $0 / 24 \mathrm{~h}$ after compulsory weaning or in the $\mathrm{CL}$ without $\mathrm{PGF}_{2 \alpha}$ treatment. Genes upregulated by PRL ( $3 \beta-$ HSD and LH-R) are indicated in red letters, whereas $20 \alpha-\mathrm{HSD}$, which is induced by $\mathrm{PGF}_{2 \alpha,}$ is indicated in blue. +++ , extremely intense expression; ++ , intense expression; + , moderate expression; $+/-$, weak expression; - , no expression. N: CL newly formed after the postpartum ovulation, $\mathrm{P}: \mathrm{CL}$ of pregnancy. 
increase in galectin-1 expression in the CLN of postpartum mice after compulsory weaning was accompanied by decreased expression of $3 \beta-\mathrm{HSD}$ and LH-R, which are known to be upregulated by PRL. At this stage, the CLN started to weakly express $20 \alpha-\mathrm{HSD}$ and it is likely due to the reduction in PRL stimulation as PRL suppresses luteal $20 \alpha-\mathrm{HSD}$ expression (Stocco et al. 2001). Therefore, the first small increase in galectin-1 expression in the CLN of compulsorily weaned mice seems to be caused by a decline of PRL stimulation resulting from the absence of the suckling reflex. This is supported by the observation that bromocriptine administration induced an accumulation of galectin- 1 both in the functional and in the regressing $\mathrm{CL}$ of nonpregnant cyclic mice and that this effect is suppressed by a single injection of PRL. Although PRL can signal through multiple pathways, it appears that the Jak 2-Stat 5 pathway is the primary route by which PRL regulates gene transcription (Goffin et al. 2002). It has been reported that galectin-1 is significantly downregulated in ERK2-deficient mice where the Jak-Stat signaling pathway is upregulated (Imamura et al. 2008). These findings support the conclusion that PRL may directly suppress the expression of galectin- 1 both in the functional and in the regressing $\mathrm{CL}$, possibly through a Jak 2-Stat 5 signaling pathway.

The expression of galectin- 1 in the compulsorily weaned mice increased again more intensely in the CLN $72 \mathrm{~h}$ after the weaning and this was associated with a strong expression of $20 \alpha-\mathrm{HSD}$ (Fig. 5A), which is known to be upregulated by $\mathrm{PGF}_{2 \alpha}$. As $\mathrm{PGF}_{2 \alpha}$ administration to the postpartum mice increased the expression of galectin-1 in the remaining CLP, which lacked LH-R (Fig. 5B), this second intense increase in galectin-1 mRNA with the intense expression of $20 \alpha-\mathrm{HSD}$ found in the CLN at $72 \mathrm{~h}$ after the weaning is likely to be caused by $\mathrm{PGF}_{2 \alpha}$ secreted from the uterus or the CL itself after a withdrawal of PRL stimulation.

Galectin-3 was also increased in the CLN of compulsorily weaned mice; however, its expression was observed later (at $72 \mathrm{~h}$ after the compulsory weaning) than an initial increase in galectin-1 in the $\mathrm{CLN}$ found at $48 \mathrm{~h}$ after the weaning (Fig. 5A). This suggests that unlike galectin-1, the PRL withdrawal may not directly influence on the galectin-3 expression in the CLN. This idea is supported by the finding that the expression of galectin-3 was unaffected by bromocriptine and PRL injection to nonpregnant cyclic mice. On the other hand, an increase in galectin-3 in the CLN at $72 \mathrm{~h}$ after compulsory weaning was accompanied with an intense expression of 20 $\alpha$-HSD, which is known to be induced by $\mathrm{PGF}_{2 \alpha}$. Because $\mathrm{PGF}_{2 \alpha}$ administration to postpartum mice induced the expression of galectin-3 in the remaining $\mathrm{CLP}, \mathrm{PGF}_{2 \alpha}$ is likely an excellent candidate to control the expression of galectin-3 as well as galectin-1 (Fig. 5B). It is known that $\mathrm{PGF}_{2 \alpha}$ functions via activation of the calcium and phospholipid-dependent protein kinase, protein kinase C (PKC), in human luteal cells (Abayasekara et al. 1993). In addition, in macrophages, PKC activator (phorbol myristate acetate) administration directly increased galectin-3 expression (Kim et al. 2003). Thus, PKC pathway may be an important cascade to induce the expression of galectin-3 as well as galectin- 1 in the CL.

Notably, the $\mathrm{PGF}_{2 \alpha}$-induced increase in galectin-3 as well as galectin- 1 was only seen in the remaining CLP that lacked an expression of LH-R but not in the CLN with an intense expression of $\mathrm{LH}-\mathrm{R}$ in the postpartum mice (Fig. 5B). This suggests that the stimulating effect of $\mathrm{PGF}_{2 \alpha}$, possibly via activation of PKC pathway, on the expression of galectins differs depending on the condition of the $\mathrm{CL}$, particularly with regard to whether it is expressing LH-R or not. Similarly, $\mathrm{PGF}_{2 \alpha}$ administration to mice at pregnancy day 17.5 failed to increase the expression of either galectin-1 or galectin-3 in the functional CLP, which intensely expressed LH-R (Fig. 5B). Thus, the upregulation of galectin- 3 as well as galectin- 1 by $\mathrm{PGF}_{2 \alpha}$ may be blocked by the signal mediated through $\mathrm{LH}-\mathrm{R}$ in the functional CLP of the pregnant mice and in the CLN of lactating postpartum mice (Fig. 5B).

As $\mathrm{PRL}$ and $\mathrm{PGF}_{2 \alpha}$ regulate luteal progesterone production through the regulation of the expression of $3 \beta-\mathrm{HSD}, \mathrm{LH}-\mathrm{R}$, and $20 \alpha-\mathrm{HSD}$, it was considered that progesterone might be a candidate molecule involved in the regulation of galectin expression. However, the administration of mifepristone, a progesterone receptor antagonist, had no effect on the galectin expression in the functional CLP of pregnant mice, suggesting that progesterone is not a key molecule for the regulation of luteal galectin expression. Nevertheless, we cannot exclude the possibility that other molecules - which are produced from luteal steroidogenic cells or other cellular components of the $\mathrm{CL}$ under the control of PRL and/or $\mathrm{PGF}_{2 \alpha^{-}}$affect the expression of galectin in a paracrine manner.

Although the function of galectin in the $\mathrm{CL}$ is still unclear, we previously demonstrated that luteal cells intensely expressing galectin-3 in the cytoplasm were resistant to apoptosis but gradually eliminated by a fragmentation of their cytoplasm (Nio-Kobayashi \& Iwanaga 2010). In the compulsorily weaned mice of this study, the number of apoptotic cells were remarkably few in the remaining CLP, which intensely expressed galectin-3 and 20 $\alpha$-HSD, whereas abundant apoptotic cells were observed in the CLN 96-120 h after the weaning, suggesting anti-apoptotic effect of galectin-3 in the CLP (our unpublished data). Takiguchi et al. (2004) demonstrated a differential regulation of apoptosis between the CLP and CLN of rats after parturition under non-lactating condition. Galectin-3 may be involved in the regulation of viability and apoptosis in luteal cells; however, further investigation is required to elucidate the exact role of galectin as well as its carbohydrate ligands in the $\mathrm{CL}$. 
In conclusion, the expression of galectin in the mouse $\mathrm{CL}$ is differentially mediated by PRL and $\mathrm{PGF}_{2 \alpha}$ (Fig. 5). The expression of both galectin- 1 and galectin- 3 is induced by $\mathrm{PGF}_{2 \alpha}$ but the effect may be abolished if the $\mathrm{CL}$ is intensely expressing LH-R. On the other hand, PRL directly inhibits the expression of galectin-1 but not that of galectin-3. As the expression of $\mathrm{LH}-\mathrm{R}$ is upregulated by PRL, a withdrawal of PRL stimulation is considered to be necessary for the $\mathrm{PGF}_{2 \alpha}$-induced expression of galectins, especially for galectin-3. Although the mechanisms involved in the regulation of luteal galectin expression as well as its function are still not fully understood, the data presented here enhance the understanding of the regulation of galectin not only in the $\mathrm{CL}$ but also potentially in other tissues under both physiological and pathological conditions.

\section{Materials and Methods}

\section{Animals and tissue sampling}

Female ddY mice were purchased from Japan SLC (Shizuoka, Japan) and maintained under controlled light (12 h light: $12 \mathrm{~h}$ darkness, lights on at $0830 \mathrm{~h}$ ) and temperature $\left(20-22^{\circ} \mathrm{C}\right)$ with free access to chow and tap water. All experiments using animals were approved by the local ethics committee of Hokkaido University (approval no. 08-0054). At least three animals were used for each group, and similar results were obtained from all animals examined. The most representative data are shown in the results.

After natural labor at days 18.5 and 19.5 of pregnancy, mice were left to lactate for 3 days. On the morning of postpartum day 3 , the pups were removed and the mothers were killed 24,48 , and $72 \mathrm{~h}$ after the weaning by cardiac examination under deep anesthesia with pentobarbital, and fresh ovaries were obtained. Other mice were treated s.c. with $\mathrm{PGF}_{2 \alpha}(25 \mu \mathrm{g}$ in ethanol; Enzo Life Sciences, Farmingdale, NY, USA) or mifepristone (RU486; $25 \mathrm{mg} / \mathrm{kg}$ in ethanol; Sigma Chemical Company) at day 17.5 of gestation, or at postpartum day 3 , and killed $12 \mathrm{~h}$ later for tissue collection.

In the experiments of bromocriptine treatment, 8-week-old females were s.c. administrated $5 \mathrm{IU}$ serum gonadotropin (Serotropin; Aska Pharmaceutical Co. Ltd., Tokyo, Japan) followed $48 \mathrm{~h}$ later by an injection of $5 \mathrm{IU}$ of human chorionic gonadotropin (hCG; Gonatropin; Aska Pharmaceutical Co. Ltd.) to synchronize the ovarian cycle. Commencing the following day (day 1), bromocriptine (Parlodel, $5 \mathrm{mg} / \mathrm{kg}$ in $0.5 \%$ carboxymethyl cellulose; Novartis Pharmaceutical Co. Ltd.) was orally administrated twice a day for 10 days. On day 9, some mice were s.c. injected with sheep pituitary PRL (50 $\mu \mathrm{g}$ in physiological saline; Sigma Chemical Company). All mice treated with bromocriptine or bromocriptine plus PRL were killed on day 10 for tissue collection. The ovaries obtained were immediately embedded in O.C.T. compound (Sakura Fintechnical Co., Ltd., Tokyo, Japan), snap frozen in liquid nitrogen, and stored at $-30{ }^{\circ} \mathrm{C}$ until use. For immunohistochemical analysis, the ovaries from bromocriptine- and bromocriptine plus PRL-treated mice were fixed with $4 \%$ paraformaldehyde at $4{ }^{\circ} \mathrm{C}$ overnight.

\section{In situ hybridization}

Two non-overlapping 45-mer antisense oligonucleotide probes for galectin-1 (Lgals1), galectin-3 (Lgals3), 3ß-HSD (Hsd3b1), $20 \alpha-H S D$ (Akr1c18), and LH-R (Lhcgr) were synthesized as reported previously (Nio-Kobayashi \& Iwanaga 2010). All probes were labeled with ${ }^{33} \mathrm{P}$-dATP using terminal deoxynucleotidyl transferase (Invitrogen). The procedure for in situ hybridization has been described previously (Nio et al. 2005). In brief, fresh frozen sections, $10 \mu \mathrm{m}$ thick, were fixed with $4 \%$ paraformaldehyde in $0.1 \mathrm{M}$ phosphate buffer for $15 \mathrm{~min}$ and acetylated with $0.25 \%$ acetic anhydride in $0.1 \mathrm{M}$ triethanolamine $\mathrm{HCl}(\mathrm{pH} 8.0)$ for $10 \mathrm{~min}$. Hybridization was performed at $42{ }^{\circ} \mathrm{C}$ for $12 \mathrm{~h}$ by adding 10000 c.p.m./ $\mu \mathrm{l}{ }^{33} \mathrm{P}$-labeled oligonucleotide probes. Then sections were rinsed at room temperature for $30 \mathrm{~min}$ in $2 \times$ SSC $(1 \times$ SSC: $150 \mathrm{mM}$ sodium chloride, $15 \mathrm{mM}$ sodium citrate) containing $0.1 \%$ sarkosyl, immersed twice at $55^{\circ} \mathrm{C}$ for $40 \mathrm{~min}$ in $0.1 \times$ SSC containing $0.1 \%$ sarkosyl, dehydrated through a graded series of ethanol, and air dried. Sections were exposed onto BioMax MR films (Kodak) for 1 day (for $3 \beta-H S D$ and $20 \alpha-H S D$ ) or for 10 days (for galectins and LH-R). The hybridized sections used for the exposure on X-ray films were stained with hematoxylin and eosin and observed under a microscope to determine the type of the CL.

The films were developed and scanned by a film scanner. The obtained images were cut into appropriate sizes by use of Photoshop Elements 8 software (Adobe Systems, Inc.). The color was reversed on this software, thus the positive signals representing each gene expression are shown in white color on each figure. The scanned images were also analyzed by Image J (Rasband, U.S. National Institutes of Health, Bethesda, Maryland, USA, http://rsb.info.nih.gov/ij/, 1997-2009) to compare the signal intensities for each gene in the individual CL. All statistical analyses were performed using Prism (GraphPad Software, La Jolla, CA, USA). Differences between groups were analyzed using one-way ANOVA and differences were considered as significant when $P<0.05$.

In situ hybridization using two non-overlapping antisense probes exhibited consistent labeling in all tissues examined. Specificity of the hybridization was also confirmed by the disappearance of the signals with an excess dose of unlabeled antisense probes.

\section{Immunohistochemistry}

The paraformaldehyde-fixed ovaries were embedded in paraffin according to the conventional method. The sections were cut from these tissue blocks and the immunohistochemistry using specific antibodies for galectin-1 and galectin-3 was performed. The detailed procedure for immunohistochemistry was previously described (Nio-Kobayashi et al. 2010).

\section{Declaration of interest}

The authors declare that there is no conflict of interest that could be perceived as prejudicing the impartiality of the research reported. 


\section{Funding}

This work was supported by a Grant-in-Aid for Young Scientists (B) (grant number 21790174) to J Nio-Kobayashi from Japan Society for the Promotion of Science.

\section{Acknowledgements}

The authors thank Prof. Kiyoshi Okuda, Okayama University, Dr Maho Amano and Dr Kazuko Hirose, Hokkaido University, and Prof. Hamish M Fraser and Dr W Colin Duncan, The University of Edinburgh, for their kind advices.

\section{References}

Abayasekara DR, Michael AE, Webley GE \& Flint AP 1993 Mode of action of prostaglandin $\mathrm{F}_{2 \alpha}$ in human luteinized granulosa cells: role of protein kinase C. Molecular and Cellular Endocrinology 97 81-91. (doi:10.1016/ 0303-7207(93)90213-4)

Bachelot A \& Binart N 2005 Corpus luteum development: lessons from genetic models in mice. Current Topics in Developmental Biology 68 49-84. (doi:10.1016/S0070-2153(05)68003-9)

Connor JR \& Davis HR 1980 Postpartum estrus in Norway rats. I. Behavior. Biology of Reproduction 23 994-999. (doi:10.1095/biolreprod23.5.994)

Gaytán F, Bellido C, Morales C \& Sánchez-Criado JE 2001 Luteolytic effect of prolactin is dependent on the degree of differentiation of luteal cells in the rat. Biology of Reproduction 65 433-441. (doi:10.1095/ biolreprod65.2.433)

Goffin V, Binart N, Touraine P \& Kelly PA 2002 Prolactin: the new biology of an old hormone. Annual Review of Physiology 64 47-67. (doi:10.1146/annurev.physiol.64.081501.131049)

Imamura O, Satoh Y, Endo S \& Takishima K 2008 Analysis of extracellular signal-regulated kinase 2 function in neural stem/progenitor cells via nervous system-specific gene disruption. Stem Cells 26 3247-3256. (doi:10.1634/stemcells.2008-0578)
Kim K, Mayer EP \& Nachtigal M 2003 Galectin-3 expression in macrophages is signaled by Ras/MAP kinase pathway and up-regulated by modified lipoproteins. Biochimica et Biophysica Acta 164 13-23. (doi:10.1016/S0167-4889(03)00045-4)

Nio J \& Iwanaga T 2007 Galectins in the mouse ovary: concomitant expression of galectin-3 and progesterone degradation enzyme ( $20 \alpha-$ HSD) in the corpus luteum. Journal of Histochemistry and Cytochemistry 55 423-432. (doi:10.1369/jhc.6A7053.2007)

Nio J, Kon Y \& Iwanaga T 2005 Differential cellular expression of galectin family mRNAs in the epithelial cells of the mouse digestive tract. Journal of Histochemistry and Cytochemistry 53 1323-1334. (doi:10.1369/jhc.5A6685.2005)

Nio-Kobayashi J \& Iwanaga T 2010 Differential cellular localization of galectin-1 and galectin-3 in the regressing corpus luteum of mice and their possible contribution to luteal cell elimination. Journal of Histochemistry and Cytochemistry $\mathbf{5 8}$ 741-749. (doi:10.1369/jhc.2010. 956227)

Stocco C, Callegari E \& Gibori G 2001 Opposite effect of prolactin and prostaglandin $\mathrm{F}(2 \alpha)$ on the expression of luteal genes as revealed by rat CDNA expression array. Endocrinology 142 4158-4161. (doi:10.1210/ en.142.9.4158)

Stocco C, Telleria C \& Gibori G 2007 The molecular control of corpus luteum formation, function, and regression. Endocrine Reviews 28 117-149. (doi:10.1210/er.2006-0022)

Takiguchi S, Sugino N, Esato K, Karube-Harada A, Sakata A, Nakamura Y, Ishikawa H \& Kato H 2004 Differential regulation of apoptosis in the corpus luteum of pregnancy and newly formed corpus luteum after parturition in rats. Biology of Reproduction 70 313-318. (doi:10.1095/ biolreprod.103.018853)

Taya K \& Greenwald GS 1982 Mechanisms of suppression of ovarial follicular development during lactation in the rat. Biology of Reproduction 27 1090-1101. (doi:10.1095/biolreprod27.5.1090)

Received 22 December 2011

First decision 2 February 2012

Revised manuscript received 29 August 2012

Accepted 6 September 2012 